Bangladesh J. Zool. 39(2): 173-185, 2011

\title{
COMMUNITY STRUCTURES OF ENDOPARASITIC HELMINTHS OF CHANNA PUNCTATUS FROM A FRESH WATER RIVER AND A POLLUTED LAGOON OF BANGLADESH
}

\author{
Md. Osman Ghani and Aminul Islam Bhuiyan*
}

Department of Zoology, University of Dhaka, Dhaka-1000, Bangladesh

\begin{abstract}
Community structures of the parasites of Channa punctatus collected from fresh water Ichamoti river (IR) and a polluted sewerage treatment lagoon (SL) near Dhaka city were determined. Out of the total 104 C. punctatus fish observed, $78.85 \%$ were parasitized by at least one species of helminth endoparasites. Twelve metazoan endoparasite (viz. six trematodes, one cestode, three nematodes and two acantho-cephalans) were recorded. Neopecoelina saharanpuriensis, Pallisentis nandai, P. ophiocephali, Ascaridia sp. were common in both sites. Euclinostomum heterostomum, an unidentified digenean, Genarchopsis ozakii, Gangesia bengalensis, Buckleynema channi were recorded from IR and Genarchopsis bangladensis, Phyllodistomum chauhani, Camallanus intestinalus from the SL fishes. Trematode was the most prevalent group and had $63.46 \%$ and $53.85 \%$ prevalence in IR and SL sample fishes, respectively. Among the parasites of IR sample, only E. heterostomum was accounted as secondary and others fall in the satellite species category; no central species accounted in the sample. In case of SL sample, no parasite species found central, Pallisentis spp. could be considered secondary and others as satellite species. A significant positive correlation was observed between the standard length of the host, and the abundance and prevalence found only for Pallisentis spp. in SL fishes, and between the standard length and the abundance of the Ascaridia sp. in IR fishes. The larger hosts were more infected than the smaller hosts. Parasites of the fish of both sites showed typical over-dispersed distribution pattern in both the sites. No parasite showed random or uniform distribution in both the sample fishes. Parasite species richness index was lower in SL sample. Prevalence and intensity were higher in both sexes in SL sample than those of in IR sample.

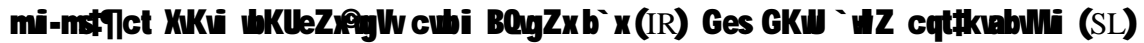

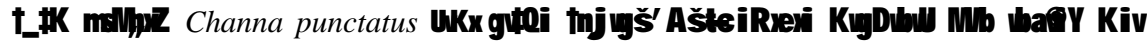
nłq $\neq Q \mid \operatorname{tg} W 104 W$ C. punctatus g

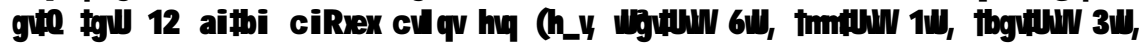
GK vs fmd y $\vee 2 W) \mid G B 12$ ai fbi ci Rxex g gła" 4 W (Neopecoelina saharanpuriensis,

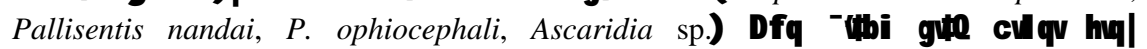
Euclinostomum heterostomum, Amb ${ }^{3}$ digenean, Genarchopsis ozakii, Gangesia

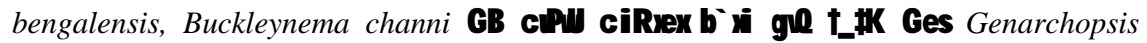
bangladensis, Phyllodistomum chauhani, Camallanus intestinalus $G B \quad W$ bWW $c \mid$ R xex †j, 抽i gQ †_ 杖 msMÖ Kivnql Wog vUUW Gi A

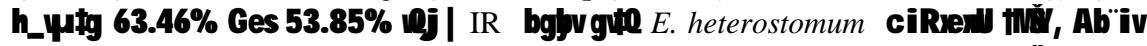
'íZZDG es tK b tK'

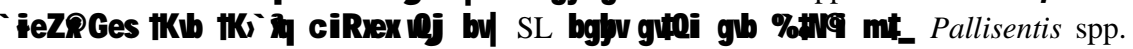

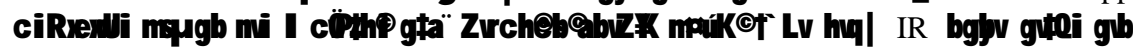

*Corresponding author: e-mail: aminul_islam89@yahoo.com 


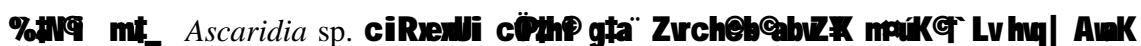

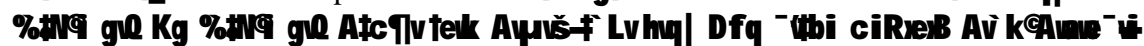

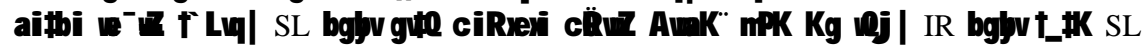

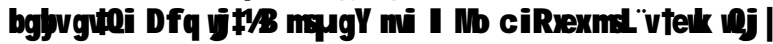

Key words: Community structure, Status, Channa punctatus, Endoparasitic helminths, Bangladesh.

\section{INTRODUCTION}

Aquatic pollution is still a problem in many freshwater and marine environments. Pollutants are being discharged continuously into the aquatic environment and there is increasing concern about their impact on the ecosystem. Organisms such as fish try to avoid the uptake of pollutants by increasing their mucus production (Sures 2008). However, this will be effective only in some cases. In addition to effects on free-living organisms, pollutants also affect the health of parasites and consequently their occurrence and distribution.

Fish generally harbor a wide range of ecto- and endo-parasites. The latter as well as their hosts might be affected in a number of ways by contaminants. Thus, pollutants might promote increased parasitism in aquatic animals, especially fish by impairing the host's immune response or favoring the survival and reproduction of the intermediate hosts (Khan and Thulin 1991). Deteriorating state of the environment in the aquatic resources is reflected by the increased degree of fish parasites and elevated metallic pollutant levels. Under natural environmental condition most fish parasites are believed to cause little or no harm. However, chronic exposure to pollutants over a period of time cause physiological, behavioral and biochemical host changes that ultimately can influence the prevalence and intensity of parasitism (Khan and Thulin 1991). The composition of the parasite fauna of fish depends on various environmental factors such as geographical location of the habitat, season of the year, physico-chemical factors of the water, the fauna present in and around the habitat etc. Pollution that reduces host vital rates will depress host population density, thereby reducing the chance of an epidemic process, or even the ability of a parasite to persist at all in a declining or low density population (Lafferty and Kuris 2004). Some pollutants are toxins and these can impair host immune systems and host vital rates, and may also impair parasite vital rates and some may even preferentially concentrate in parasite tissues (Sures et al. 1997). Pollution and other man-made alterations of the aquatic environment may affect a parasite community directly by acting on free-living parasitic stages or on ectoparasites, or indirectly by acting on the intermediate or the definitive host 
population (Poulin 1992). So, parasites display individual, population and community level alterations in polluted environments (Marcogliese 2005).

Water pollution directly interferes with fish health and thus it can change the parasite community of fish and also may regulate the composition of parasite community in a specific type of fish. Investigation of pollution effect on parasitic communities in aquatic environment is scarce and seldom in Bangladesh. But recently increasing interest has been observed among scientists in this field for their awareness about environmental pollution and its negative impact on world biotic fauna as well as to our own. Parasites can also be used as an indicator for getting information about environmental pollution (MacKenzie 1999). So, the present work was undertaken to investigate the parasite community structure with comparative parasite species diversity and richness of endoparasites of the host snakehead fish Channa punctatus (Bloch 1793) (Channidae) collected from two different water bodies of varying water quality in Bangladesh.

\section{OBJECTIVE}

The objective of the present study was to determine the community structure of the parasites of Channa punctatus collected from a fresh water river and a polluted sewerage lagoon near Dhaka city.

\section{MATERIAL AND METHODS}

The host C. punctatus was sampled from two different water bodies near Dhaka, selected according to their different water quality as- Polluted water: Sewage treatment lagoon (SL) of Water and Sewerage Authority (WASA), Pagla, Narayanganj; and Unpolluted fresh water: Ichamoti River (IR), near the village Saperchor, Munshiganj.

A total of 104 (52 from each site) C. punctatus individuals was collected from the local fishermen in between September 2010 and March 2011. The samples were collected as live from their habitat water and immediately brought to the Parasitology laboratory of the Department of Zoology, University of Dhaka.

Investigation on helminth parasites: The examination was aimed to study the infection in the fish by endoparasitic helminths. Sex, size and organwise infection of the fish by each type of parasite was recorded. Measurements and sexes were noted before autopsy. All the parasites from each organ were sorted, cleaned and counted. They were preserved in 70\% alcohol. Berland's (1982) methods were used for staining and mounting.

Calculation and data analysis: To describe the structure of infra and component-communities, the data related to parasite abundance, prevalence, 
intensity and species richness were recorded following Bush et al. (1997). The classification of the species was done according to the importance value for the community (Bush and Holmes 1986) as Central species (Cen) $=$ present in more than $66.6 \%$ of the total number of fish analyzed; Secondary species (Sec) $=$ present between 33.3 and $66.6 \%$ of samples; and Satellite species (Sat) = lower than $33.3 \%$ of samples.

Two criteria, namely Green's dispersion index (GI) and index of dispersion (DI) were used to evaluate the dispersion pattern of parasite species. The dispersion index was tested using statistical ' $d$ '. Distribution was classified as aggregated when $d>1.96$; regular when $d<-1.96$ and random when $d<1.96$ (Ludwig and Reynolds 1988).

GI was calculated using the formula: $G I=\frac{\frac{\mathrm{s}^{2}}{\bar{x}}-1}{\mathrm{n}-1}$

Green's index take a value of 1.0 at maximum clumping, 0 for random distribution and $-1 / n-1$ for a perfectly uniform distribution.

DI was calculated using the following formula: $D I=\frac{\mathrm{s}^{2}}{\bar{x}}$

The DI indicates random pattern when $\bar{x}=s^{2}$, clumped/aggregated pattern when $\bar{x}<\mathrm{s}^{2}$ and uniform pattern when $\bar{x}>\mathrm{s}^{2}$.

For both indices, $n$ is the total number sampling units, $\bar{x}$ is the sample mean and $s^{2}$ is the sample estimated variance.

Pearson linear correlation coefficient $(r)$ was computed to determine possible correlations between the host's standard length and the prevalence of infestation of each parasite species (Zar 1996). Spearman's rank correlation coefficient $\left(r_{s}\right)$ was calculated to determine possible correlations between the total length of hosts and abundance of parasites.

Simpson's index (Simpson 1949) was used to evaluate for both richness and proportion of parasites within the samples, was counted by the formula:

$\lambda=\sum p_{i}^{2}$ where, $p_{\mathrm{i}}$ is the proportional abundance of the $i$ th species.

Simpson's Index gives the probability of any two individuals drawn at random from an infinitely large community belonging to different species. Simpson's Index (ג) and diversity are negatively related.

Shannon's index (Shannon and Weaver 1949), which measures the "information content" of a sample unit, was used to measure the diversity, was calculated by the formula:

$H^{\prime}=-\sum p_{i} l n p_{i}$ where, $p_{i}$ is the proportion of individuals found in the $i$ th species and $\ln$ is the natural logarithm.

A greater number of species and a more even distribution both increase diversity as measured by $H^{\prime}$. 
From the sample data, Brillouin's index was calculated using the formula:

$H_{B}=\frac{\ln (N !)-\Sigma \ln \left(n_{i} !\right)}{N}$ where, $N$ is the total number of individuals and $n_{i}$ is the number of individuals in the ith species.

The most commonly used index of evenness is that based on the ShannonWiener index (Pielou 1977) was calculated by the formula:

$$
E_{p}=\frac{H^{x}}{\ln (S)}
$$

Heip (1974) proposed evenness index was calculated by the formula:

$$
E_{h}=\frac{e^{H^{*}}-1}{S-1}
$$

Kruskal-Wallis test was performed to compare the influence of habitats (fresh water river and polluted sewage lagoons) on parasitism levels (Zar 1996).

The analysis included only component parasite species, whose prevalence was greater than 10\% (Bush et al. 1990). Community structure of parasites has been determined as a function of host habitats, sizes, sexes. We mainly used prevalence, intensity, diversity index and species richness to chalk out community structure of parasites of the host fish.

Under the dissecting microscope two species of Pallisentis ( $P$. nandai and $P$. ophiocephali) looked similar. The morphological characteristics became apparent only when the parasites were studied under high magnification using a compound microscope. That is why for calculation these two species have been referred to as Pallisentis spp. One nematode, Ascaridia could not be identified to species level and one trematode could not be identify to genus level even.

Statistical tests were conducted by using XLSTAT 2011 (Kruskal-Wallis test) and SPSS 14.0 (Pearson linear correlation and Spearman's rank correlation) software package. The statistical significance level adopted was $\mathrm{p} \leq 0.05$.

\section{RESULTS AND DISCUSSION}

Of the total 104 Channa punctatus fish observed 82 (78.85\%) were parasitized by at least one or more species of helminth endoparasite. Twelve metazoan endoparasite were recorded though one of them (digenean) could not be identified. The parasites recorded were six digeneans (Euclinostomum heterostomum, Neopecoelina saharanpuriensis, Genarchopsis ozakii, Genarchopsis bangladensis, Phyllodistomum chauhani and unidentified one), one cestode (Gangesia bengalensis), three nematodes (Buckleynema channi, Ascaridia sp., Camallanus intestinalus) and two acanthocephalans (Pallisentis nandai and $P$. ophiocephali). Of the 12 parasites recovered, four were common (Neopecoelina saharanpuriensis, Pallisentis nandai, P. ophiocephali and Ascaridia 
sp.) in both sites. Euclinostomum heterostomum, an unidentified digenean, Genarchopsis ozakii, Gangesia bengalensis and Buckleynema channi were recorded from the fishes of IR and Genarchopsis bangladensis, Phyllodistomum chauhani and Camallanus intestinalus from the fishes of SL.

Twelve species of helminth endoparasites were collected from fishes of both the sites. Trematodes were the most abundant and $63.46 \%$ and $53.85 \%$ hosts were found infected in IR and SL sample fishes, respectively. E. heterostomum was the dominant species (36.39\% of all parasites) in IR fishes. Whereas, in SL sample fishes dominant species was $P$. nandai ( $24.21 \%$ of all parasites). In the parasites of IR sample only E. heterostomum was accounted as secondary (prevalence $=40.38 \%$ ) and others fall in the satellite species category; no central species accounted in this sample. In case of SL sample, no parasite species showed as central, but one genus (Pallisentis) could be considered secondary (prevalence $=46.15 \%)$ and others as satellite species (Table 1$)$.

Pollution and other man-made alterations of the aquatic environment may affect a parasite community directly by acting on free-living parasitic stages or on ectoparasites, or indirectly by acting on the intermediate or the definitive host population (Poulin 1992). Pollutants might influence, directly or indirectly, the prevalence, intensity and pathogenicity of a parasite (Khan and Thulin 1991). So the increasing prevalence and intensity in aquatic lagoon is not surprising. Pollutants might promote increased parasitism in aquatic animals, especially fish by impairing the host's immune system or favoring the survival and reproduction of the intermediate hosts. The intensities and prevalence of parasitic fauna from polluted environment increase with a wide range of pollutants. This appears to be due to an increase in host susceptibility. Toxins somehow impair mucus production which is fish's main defense against parasites (Khan 1990). In the present observation the higher prevalence and intensity of parasitic infection were recorded and this might be due to immune suppressor toxins and heavy metal present in that aquatic environment which directly or indirectly decreased the host immune system and increased susceptibility to parasitic infection.

The prevalence of trematode (63.46\%) infestation was the highest in IR fishes which was followed by nematodes $(34.62 \%)$, acanthocephalans $(13.46 \%)$ and cestodes $(5.77 \%)$. Whereas, SL fishes were widely infested by trematodes $(53.85 \%)$ then followed by acanthocephalans $(46.15 \%)$ and nematodes $(34.62 \%)$. No cestode infection was observed in polluted SL sample specimens (Fig 1). 


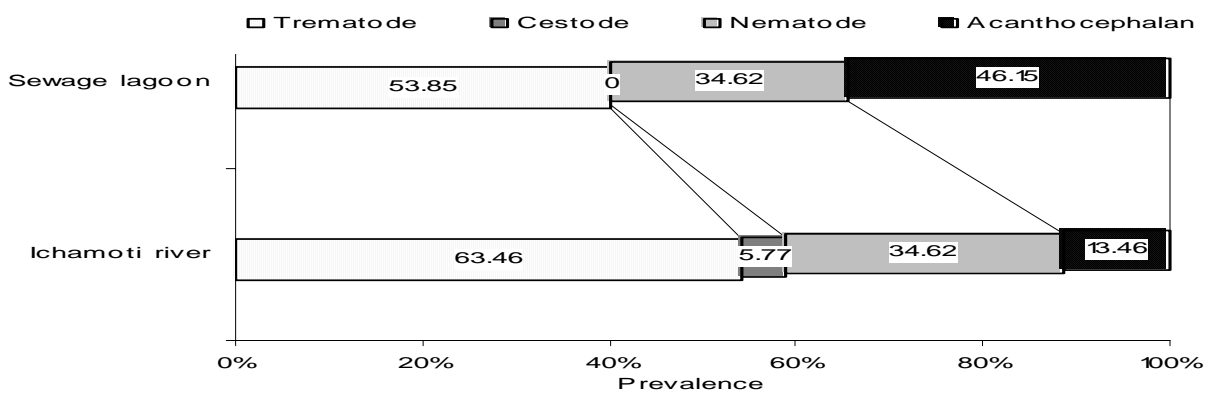

Fig. 1. Prevalence of different groups of parasite of C. punctatus in two sampling sites.

Most nematode parasites of $C$. punctatus were highly sensitive to pollution since they only thrived at unpolluted sites. The presence of some nematodes in the polluted sites may be made possible by their possession of a thick cuticle, which enables them to withstand the harsh conditions.

Parasites of fishes of both sites had shown typical over dispersed type of distribution pattern. In IR sample $N$. saharanpuriensis showed the highest dispersion index value $(\mathrm{DI}=7.714)$ suggested their highest clumping distribution in fishes and the d-value for other species of IR fishes also suggested their aggregated distribution. In SL sample Pallisentis spp. showed the highest dispersion index value $(\mathrm{DI}=6.313)$ and other species had also aggregated distribution. No parasite species showed randomness or uniform distribution pattern from the both sample fishes (Table 2).

Aggregated distribution of the parasite population is considered one of the most common features of metazoan parasite infections (Poulin 1993). Values obtained from two indices revealed a high aggregation level, confirming a characteristic typical of metazoan parasite populations. This aggregated distribution pattern, according to Holmes (1990) may be due to increasing reproductive efficiency of some adult species of parasites and occupation of a different niche in the intestine of host. According to Dobson (1990), this distribution pattern improves the opportunity to infect the host.

Parasite species diversity was accounted by three well known diversity indices. These indices indicated that species richness index decreased in sample fishes of polluted site (SL). Simpson's index $(\lambda)$ was lower in IR sample $(\lambda=0.184)$ than that of SL sample fishes $(\lambda=0.282)$, which indicated that IR fishes were infested by more parasite species than SL fishes. Shannon's index $\left(H^{\prime}\right)$ and Brillouin's index $\left(\mathrm{H}_{B}\right)$ were higher in case of IR parasite community than that of SL, indicated that the parasite community from IR sample was well diverged than the SL sample fishes. Evenness of parasite distribution was also tested by Pielou evenness index $\left(\mathrm{E}^{\mathrm{P}}\right)$ and Heip evenness index $\left(\mathrm{E}^{\mathrm{H}}\right)$, which showed a higher 


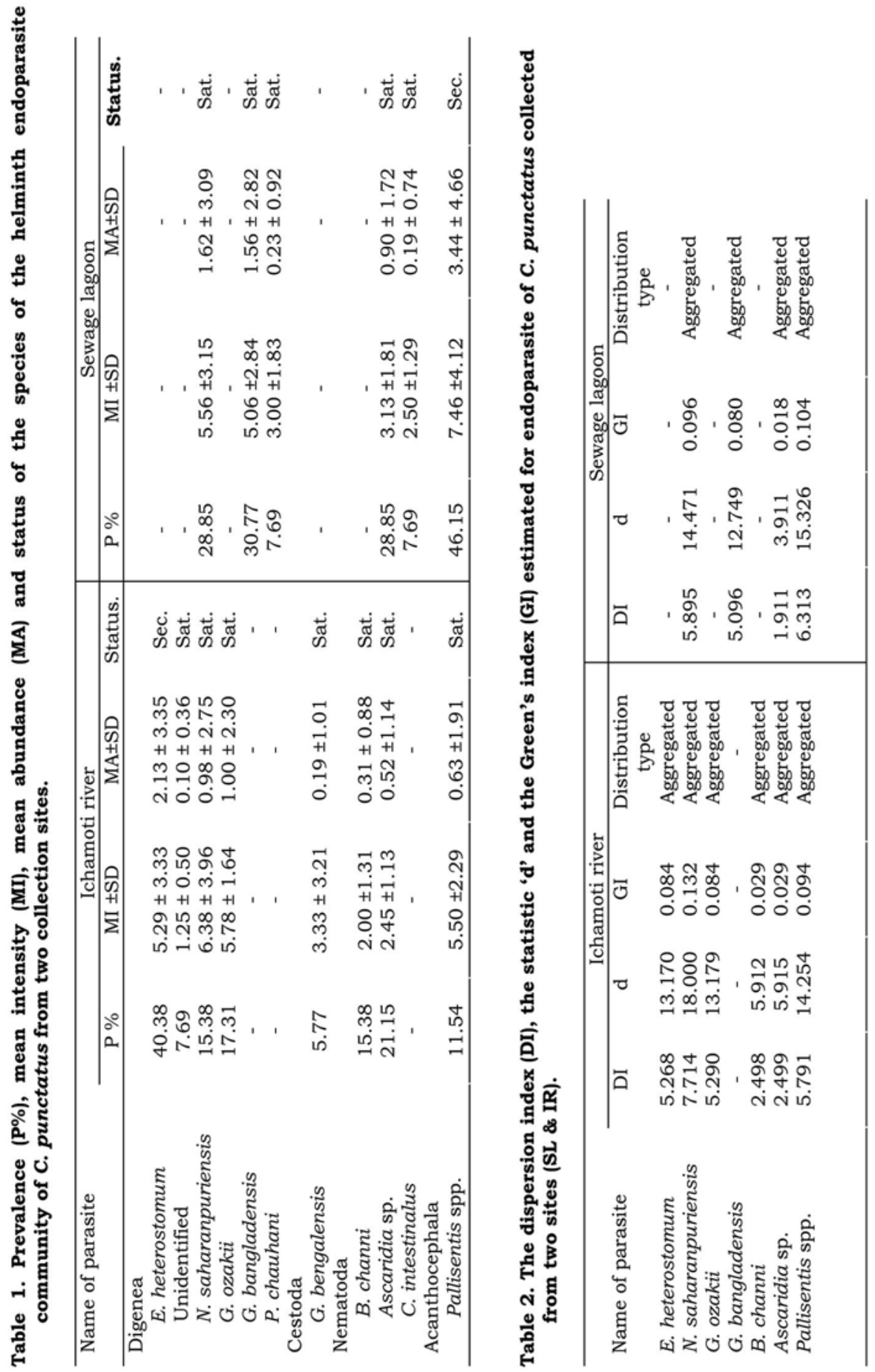


evenness indices in IR samples $\left(\mathrm{E}^{\mathrm{P}}=0.936, \mathrm{E}^{\mathrm{H}}=0.857\right)$ than SL sample $\left(\mathrm{E}^{\mathrm{P}}=0.806\right.$, $\mathrm{E}^{\mathrm{H}=0.647)}$ fishes that meant community structure was well developed by increasing evenness of all parasite species among the IR sample fishes (Table 3).

Table 3. Diversity measures of helminths endoparasite component communities in C. punctatus.

\begin{tabular}{lcc}
\hline Index/Evenness & Ichamoti river & Sewage lagoon \\
\hline Simpson index $(\lambda)$ & 0.184 & 0.282 \\
Shanon-Weiner index $\left(\mathrm{H}^{\prime}\right)$ & 1.946 & 1.444 \\
Brillouins index $\left(\mathrm{H}_{\mathrm{B}}\right)$ & 1.703 & 1.415 \\
Pielou evenness index $\left(\mathrm{E}^{\mathrm{P}}\right)$ & 0.936 & 0.806 \\
Heip evenness index $\left(\mathrm{E}^{\mathrm{H}}\right)$ & 0.857 & 0.647 \\
Species richness & 9 & 7 \\
\hline
\end{tabular}

Rich and most diverse helminth communities were found in the unpolluted sites, while the helminth communities of the polluted site were depauperate assemblages with low levels of species richness and diversity, and relatively low abundance of most of the constituent species. Polluted water may also act directly on intermediate hosts and definitive hosts. A pollutant may also kill sensitive free-living stages of the parasite (Evans 1982). Trace metals in sewage sludge reduced the survival of free-living cercariae and miracidia, leading to a lower prevalence of the digenea in snails (Siddall and Clers 1994). The results are consistent with the findings of Sulgotowska and Styczynska-Jurewicz (1987) who recorded reduction in species richness from 12 to 4 due to municipal and industrial sewage.

Infection in relation to host's standard length: Correlation between the host standard length, and the prevalence and abundance of parasites were observed by determining Pearson's linear correlation coefficient ( $r$ ) and Spearman's rank correlation coefficient $\left(r_{s}\right)$. According to Pearson's coefficient correlation and Spearman's rank correlation coefficients, a significant positive correlation was observed between the host standard length and the abundance only for Ascaridia sp. $\left(\mathrm{r}_{\mathrm{s}}=0.322, \mathrm{P}<0.05\right)$ in IR sample specimen, but not significant to prevalence. While SL samples showed a significant positive correlation between host standard length and the abundance and prevalence only for Pallisentis spp. $\left(\mathrm{r}=0.312, \mathrm{p}<0.05 ; \mathrm{r}_{\mathrm{s}}=0.308, \mathrm{P}<0.05\right)$. Other parasites showed positive correlation between host standard length and the prevalence and abundance of parasite from both the sample fishes but not significant (Table 4). 
Table 4. Values of Pearson's correlation coefficients (r) and Spearman's rank correlation coefficients $\left(r_{s}\right)$ to evaluate the relationship between abundance and prevalence with standard length of $C$. punctatus

\begin{tabular}{l|cccc|cccc}
\hline \multirow{2}{*}{ Parasite } & \multicolumn{4}{|c|}{ Ichamoti river } & \multicolumn{4}{c}{ Sewage lagoon } \\
\cline { 2 - 9 } & $\mathrm{r}$ & $\mathrm{p}$ & $\mathrm{r}_{\mathrm{s}}$ & $\mathrm{p}$ & $\mathrm{r}$ & $\mathrm{p}$ & $\mathrm{r}_{\mathrm{s}}$ & $\mathrm{p}$ \\
\hline E. heterostomum & 0.161 & 0.255 & 0.253 & 0.070 & - & - & - & - \\
N. saharanpuriensis & 0.053 & 0.705 & 0.003 & 0.985 & 0.142 & 0.315 & 0.201 & 0.152 \\
G. ozakii & 0.243 & 0.083 & 0.212 & 0.131 & - & - & - & - \\
G. bangladensis & - & - & - & - & 0.138 & 0.329 & 0.109 & 0.440 \\
B. channi & 0.011 & 0.940 & 0.059 & 0.676 & - & - & - & - \\
Ascaridia sp. & 0.258 & 0.065 & 0.322 & $0.020^{*}$ & 0.026 & 0.857 & 0.006 & 0.969 \\
Pallisentis spp. & 0.110 & 0.438 & 0.107 & 0.449 & 0.312 & $0.024^{*}$ & 0.308 & $0.027^{*}$ \\
\hline
\end{tabular}

p: significance level; * : significant values.

In the present study, host size was not always correlated with the prevalence and abundance of the parasite species, while at the infracommunity level the total number of parasite individuals, in addition to their diversity and richness, generally shows positive correlation with host size. As pointed out by Poulin (2000), these patterns cannot be generalized because in many host-parasite systems the correlations are positive, but weak and nonsignificant. Also, ontogenetical changes in feeding behavior might influence parasite prevalence and abundance in the different host size classes (Saad-Fares and Combes 1992). The standard length of fish can be related to their age (Shotter 1976). As the fish grows, several changes take place in its behavior and biology, which can influence the parasite fauna (Takemoto et al. 1996). Factors like quantity and type of food consumed, size of the prey, greater exposure time, the increase in the surface area of the body, and the changes in habitat according to age, can be responsible for the increment in the prevalence and abundance with the advance of the host's age (Hanek and Fernando 1978).

In this study, the hosts of bigger length were found to be more infected than the smaller hosts. This might be due to that the bigger ones cover wider areas in search of food. As a result, they take more food than the smaller ones and this exposed them to infection by more parasites.

Infection in relation to host's sex: In IR sample fishes 33 were female of which $28(84.84 \%)$ and $10(52.63 \%)$ out of 19 male were parasitized by at least one species of parasite, presenting a mean intensity of $8.57 \pm 3.11$ and $6.50 \pm 2.74$ parasite per female and male, respectively. On the other hand, in sample specimens from SL 32 were female of which 30 (93.75\%) and 14 out of 20 observed male $(70.00 \%)$ were parasitized by at least one species of parasite, presenting a mean intensity of $10.77 \pm 3.95$ parasite per female and $6.43 \pm 2.31$ parasite per male hosts (Fig 2). 


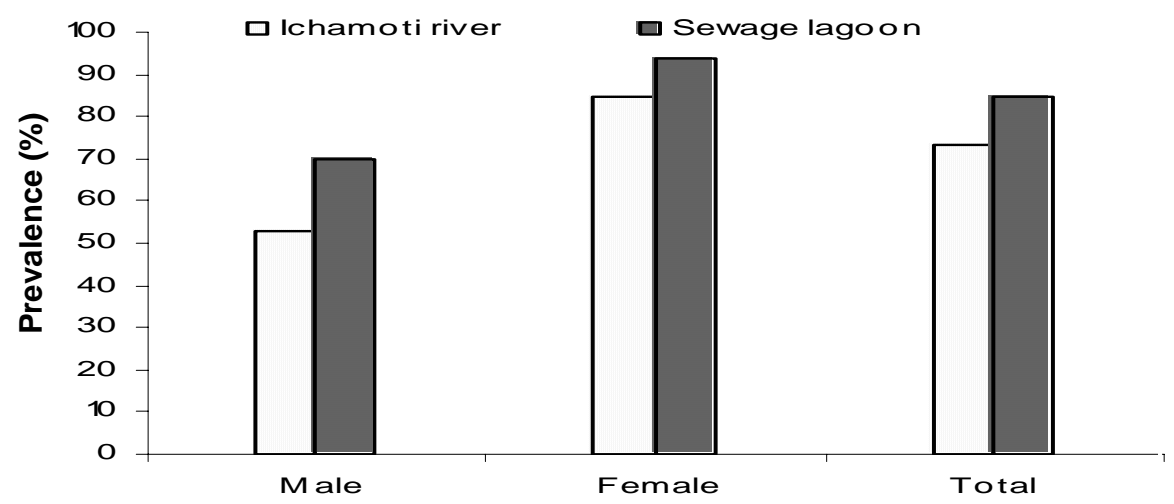

Fig. 2. Prvalence of infection in male and female hosts of C. punctatus

Host sex can influence parasitism levels due to the behavior and physiological differences between them (Esch et al. 1988). In the present study, the prevalence and intensity of all parasites as a whole varied in sexes of the host. This might be due to the physiological state of the females, as most gravid females had reduced resistance to infection by parasites. In addition, their increased rate of food intake to meet their food requirements for the development of their egg might have exposed them to more contact with the parasites, which subsequently increased their chance of being infected.

Habitats: For the three common parasites from both the sample hosts Kruskal-Wallis test was done to evaluate the role of habitats on parasitic infestation. According to the test Pallisentis spp. $(\mathrm{H}=12.455, \mathrm{P}<0.05)$ presented a significant difference in intensity of infestation in relation to the habitats (Table $5)$. The two other common species ( $N$. saharanpuriensis and Ascaridia sp.) did not show significant difference $(\mathrm{P}>0.05)$ in intensity of infestation in relation to habitats.

Table 5. Values of the Kruskal-Wallis test $(\mathrm{H})$ of three common parasites and corresponding level of significance.

\begin{tabular}{lcl}
\hline Parasite & $\mathrm{H}$ & $\mathrm{p}$ \\
\hline N. saharanpuriensis & 2.325 & 0.127 \\
Ascaridia $\mathrm{sp}$ & 1.584 & 0.208 \\
Pallisentis spp. & 12.455 & $0.0001^{*}$ \\
\hline
\end{tabular}

p: significance level; * : significant values.

Some parasites requiring complex life history patterns will be absent along with pollution related disappearance of their vector hosts. Generally, only the parasites needing a single host will be present in such systems. Our study also 
suggests acanthocephalan parasites are more prevalent among the fishes from polluted environment which requires one host for completing its life cycle.

\section{CONCLUSION}

Community structure of the parasites of C. punctatus of fresh water Ichamoti river varied from that of a polluted sewerage lagoon near Dhaka city. Some parasites were common in both the sites while others were site specific. Parasite species richness index was lower in SL fishes. Parasites of the fishes of both the sites showed typical over the dispersed pattern of distribution.

\section{LITERATURE CITED}

BERLAND, B. 1982. Basic techniques involved in helminth preservation. In proceeding of workshop on "Technology as applied to museum parasite collections." ICOPA V-1982. Toronto, Canada: $1-15$.

BUSH, A.O. and HOLMES, J.C. 1986. Intestinal helminthes of lesser scaup ducks: patterns of association. Canadian J. Zool. 64: 132-141.

BUSH, A.O., AHO, J.M. and KENNEDY, C.R. 1990. Ecological versus phylogenetic determinants of helminth parasite community richness. Evolutionary Ecology 4: 1-20.

BUSH, A.O., LAFFERTY, K.D., LOTZ, J.M. and SHOSTAK, A.W. 1997. Parasitology meets ecology on its own terms: Margolis et al. revisited. J. Parasitol. 83(4): 575-583.

DOBSON, A.P. 1990. Models of multi-species parasites-host communities. In ESCH, GW., BUSH, AO. and AHO, J. (Eds.). Parasite communities: patterns and process. New York: Chapman and Hall. pp. 261-287.

ESCH, G.W. et al. 1988. Patterns in helminth communities in freshwater fish in Great Britain: alternative strategies for colonization. Parasitology, New York. 96: 519-532.

EVANS, N. A. 1982. Effects of copper and zinc upon the life cycle of Notocotylus attenuatus (Digenea: Notocotylidae). Int. J. Parasitol. 12: 363-369.

HANEK, G., FERNANDO, C.H. 1978. The role of season, habitat, host age, and sex on gill parasites of Ambloplites rupetris (Raf). Can. J. Zool. 56: 1251-1253.

HEIP, C. 1974. A new index measuring evenness. Journal of Marine Biological Association 54: $555-557$

HOLMES, J.C. 1990. Competition, contacts and other factors restricting niches of parasitc helminths. Annales de Parasitologie Humaine et Comparee 65: 69-72.

KHAN R. A. 1990. Parasitism in marine fish after chronic exposure to petroleum hydrocarbons in the laboratory and to the Exxon Valdez oil spill. Bull. Environ. Contam. Toxicol. 44: 759-763.

KHAN, R. A. and THULIN, J. 1991. Influence of pollution on parasites of aquatic animals. Adv. Parasitol. 30: 201-238.

LAFFERTY, K. D. and KURIS, A. M. 2004. Parasitism and environmental disturbances. Chapter 7:113-123

LUDWIG, J.A. and REYNOLDS, J.F. 1988. Statistical ecology: a primer on methods and computing. New York: Wiley-Interscience Publications. pp. 337.

MacKENZIE, K. 1999. Parasites as pollution indicators in marine ecosystems: a proposed early warning system. Marine Pollution Bulletin. 38: 955-959. 
MARCOGLIESE, D.J. 2005. Parasites of the super organism: are they indicators of ecosystem health? Int. J. Parasitol. 82: 389-399.

PIELOU, E.C. 1977. Mathematical Ecology. Wiley, New York.

POULIN, R. 1992. Toxic pollution and parasitism in freshwater fish. Parasitol. Today 8: 58-61.

POULIN, R. 1993. The disparity between observed and uniform distributions: a new look at parasite aggregation. Int. J. Parasitol. 23(7): 937-944.

POULIN, R. 2000. Variation in the intraspecific relationship between fish length and intensity of parasitic infection: biological and statistical causes. J. Fish. Biol. 56(1): 123-137.

SAAD-FARES, A. and COMBES, C. 1992. Abundance/host size relationships in a fish trematode community. J. Helminthol. 66(3): 187-192.

SHANNON, C.E. and WEAVER, W. 1949. The Mathematical Theory of Communication. University Illinois Press, Urbana, IL.

SHOTTER, R.A. 1976. The distribution of some helminth and copepod parasites in tissues of whiting Merlangus merlangus L. from Manx water. J. Fish Biol., Oxford. 8: 101-117. .

SIDDALL, R. and CLERS, S. D. 1994. Effect of sewage sludge on the miracidium and cercaria of Zoogonoides viviparus (Trematoda: Digenea). Helminthologia 31: 143-153.

SIMPSON, E.H. 1949. Measurement of diversity. Nature 163: 688.

SULGOSTOWSKA, T. and STYCZYNSKA-JUREWICZ, E. 1987. Helminth parasites of flounder Platichthys flesus L. in highly eutrophicated gulf of Gdansk, Southern Baltic Sea. 2nd International Symposium of Ichthyoparasitology. Actual Problems in Fish Parasitology, Tihany, Hungary, 27 September-3 October. 93 pp. Budapest, Hungary, Veterinary Medicine Research Institute, Hungarian Academy of Sciences.

SURES, B., TARASCHEWSKI, H. and RYDLO, M. 1997. Intestinal fish parasites as heavy metal bioindicators: a comparison between Acanthocephalus lucii (Palaeacanthocephala) and the zebra mussel, Dreissena polymorpha. Bulletin of Environmental Contamination and Toxicology 59: 14-21.

SURES, B. 2008. Environmental Parasitology. Interactions between parasites and pollutants in the aquatic environment. Journal of Helminthology 15: 434-438.

TAKEMOTO, R.M. et al. 1996. Comparative analysis of the metazoan parasite communities of leatherjackets, Oligoplites palometa, O. saurus, and $O$. saliens (Osteichthyes: Carangidae) from Sepetiba Bay, Rio de Janeiro, Brazil. Rev. Bras. Biol. Sao Carlos. 56(4): 639-650.

ZAR, J.H. 1996. Biostatistical Analysis. New Jersey: Prentice-Hall, Inc. p. 662. 